Article

\title{
Tourism Information Diffusion through SNSs: A Theoretical Investigation
}

\author{
Ting Liu ${ }^{1,2}$, Jianhong $\mathrm{Xia}^{3, * \mathbb{C}}$ and Lesley Crowe-Delaney ${ }^{4}$ \\ 1 Institute of Remote Sensing and Earth Sciences, Hangzhou Normal University, Hangzhou 311121, China; \\ tingliu_hz@hznu.edu.cn \\ 2 Zhejiang Provincial Key Laboratory of Urban Wetlands and Regional Change, Hangzhou 311121, China \\ 3 School of Earth and Planetary Sciences, Curtin University, Perth 6845, Australia \\ 4 Faculty of Business and Law, School of Marketing, Curtin University, Perth 6845, Australia; \\ lesley.crowe-delaney@curtin.edu.au \\ * Correspondence: c.xia@curtin.edu.au
}

Received: 16 December 2019; Accepted: 19 February 2020; Published: 26 February 2020

check for updates

\begin{abstract}
Social networking sites (SNSs) are known to have a role in promoting tourism and influencing how it is marketed to consumers, but there seems to be few deep analyses of SNS's efficacy in tourists' decision making and destination promotion. To address this, we present Tourism Information Diffusion Ecosystem (TIDE), a novel theoretical framework to help understand this system of tourism SNS information diffusion. TIDE defines who participates in the system, what roles participants play in distributing tourist information contained within user-generated content, how content within a network is distributed, and if this user-generated information, once diffused, has been transferred into tourists' visiting actions, and the reasons why these actions have been generated. We discovered user typologies and the powerful characteristics of this network structure to be important factors affecting visiting actions in choosing particular tourist destinations.
\end{abstract}

Keywords: tourism system theory; information network analysis; tourism information diffusion; user-generated content

\section{Introduction}

Social networking sites (SNSs), and the information they reveal, are of great value in tourism destination marketing [1]. Social media postings, such as blogs and microblogs, collaborative projects, and community content, through which tourists share their feedback as user-generated content (UGC) and electronic word-of-mouth, are considered to be reliable sources of information about travel experiences, recommendations and product reviews [2].

Social network analysis and information diffusion has been applied to many areas of tourism research, including the willingness to share tourist information [3], leadership of information sharers [4], ecosystem networks [5], online travel marketing [6,7], knowledge communication and transfer within a destination network [8], collaboration and cooperation of a stakeholder network in tourism destinations [9,10], creative entities of stakeholder networks in tourism destinations [11], tourism facility management [12], policy diffusion [13] and tourism research collaboration [14]. The literature is significant on tourism information diffusion from a mathematical, social or physics perspective [15], however few studies have focused on:

- evaluating SNSs' efficacy in tourism destination promotion quantitatively, and;

- the mechanisms for sharing tourism information through SNS platforms from a holistic and systematic point of view [16]. 
New methods, models and theories are needed to understand this innovative and complex information distribution channel.

To this end, we present Tourism Information Diffusion Ecosystem (TIDE), our theoretical framework inspired by the whole tourism system [17], the business ecosystem of holistic sustainable systems [18] and General System Theory [19]. TIDE incorporates earlier research in information science, network science and tourism studies to understand the evolution of tourism information dissemination along social networks. TIDE defines who participates, what roles participants play within UGC tourist information distribution, how UGC is distributed along social networks, and if the user-generated content has transferred into tourists' visiting actions, the reasons why these actions have been generated. We will define the structure, process, function and outcome of TIDE.

The objectives of this study are threefold:

- Develop a theoretical framework for defining TIDE, its components and the components' interrelationships;

- Conduct social network connectivity analyses, including average degree, shortest path, and network centralisation, due to information diffusion processes;

- Evaluate the factors affecting visiting action to tourist destinations as a result of SNS users' information diffusion.

We used the number of close followers of each influencer as a proxy for the number of visiting actions to a destination. Influencers are trip diarists who have visited a particular destination, posting experiences and comments into their trip diaries. Close followers are those who post comments on trip diaries on SNSs and have visited the same tourist destinations later.

TIDE provides a theoretical framework for understanding tourism information diffusion through SNSs. Our case study applied TIDE to examine trends and investigate the influence of tourist information diffusion along social networks on the future tourist visiting actions to a destination, potentially providing opportunities for the tourism and hospitality sectors to build business plans and be better equipped for change.

\section{Literature Review}

Information diffusion along SNSs is a complicated process, attracting researchers from many different disciplines. In this review, we will focus on research into diarising travel in social media, tourist information diffusion along social media networks, tourist visiting action behaviour and tourism systems.

\subsection{Tourism Planning and Chinese Visitor Behaviour}

In 2018, research highlighted the lacunae in understanding Chinese visitors' travel behaviour in unique Western Australia (WA), a state which covers 33\% of Australia [20]. Other research has highlighted the economic risks of single market focus strategies, also due to tourism research gaps in understanding such markets [21]. Proper tourism planning is essential [22], avoiding inappropriate and unresearched strategies $[23,24]$, while using proven methods that have been transformed due to SNSs and big data use for research. Hall [25] pointedly remarks, 'Theory-based interventions, facilities and understanding of what works across different behaviours, contexts, geographical regions and populations' are essential'. Regarding Western Australia, in 2016 at a Margaret River conference, Hall called tourism WA's new 'mining'. He was right, tourism mirrors mining where, as a potential junior industry player, there is a spike of income (tourists) [26,27], as well as the associated plummeting figures as markets change.

Between consumerism, business-to-business networks that include advertising and marketing, the latter arguably slow to act and acting as a third party, the tourism-driven consumer is clearly the driver as a deep and large body of research curated by Sigala and Gretzel [28] indicates. It is this alternative platform of tourism business that destinations such as Western Australia must consider, 
as the previous advertising and market knowledge is fast becoming passé [29], as are pencilled-in accommodation registers. How we understand this 'new' tourist-driven approach, particularly for such two polemics of culture and distance, China and WA, is what will improve a multitude of tourism provider gaps previously acknowledged in research [20].

Multi-lingual and wellknown travel agencies are few in Western Australia, as are tourism, hospitality and accommodation providers. Those providers with over extended or no skills in this area still need to sustain their viability in this highly lucrative but competitive industry. Tourism provision is often a one-off experience, but the sustainability of the industry, the destinations visited and the business communications and business-to-business networks are all components of the digitalised and networked tourism business ecosystem, notwithstanding the consumers' roles in this system, something less influential before the rise of internet social media. Chinese SNS participants, in their rapid uptake of social media to remain 'connected' (where they were once disconnected, as late as 2006), have shown that being involved in these networks is highly profitable, and Chinese businesses have exploited the opportunity [30].

\subsection{Business Ecosystems}

The importance of SNSs and Chinese consumerism cannot be underestimated. Greeven and Wei [31] list companies, such as Alibaba, Baidu, Tencent and Xiaomi, which attest to the benefits of internet market disruption and diverted profit-making. Business ecosystems (shangyeshengtai) put simply, are networks of suppliers, providers of businesses, connected by related needs and wants in such businesses and where relationships are loosely or strategically created. As such, they are integral in the Chinese business economy. Fundamentally, it can be argued that due to its historic business systems and cultural geography, Chinese business ecosystems work well in the overall communication-based economy, initially a word-of-mouth system.

Prominent geographer Tuan Yi Fu [32] noted that distance in terms of 'space and place' in China creates problems for people who, for centuries, have been used to being connected in close proximity to friends and loved ones. Social relationships, too, are bound to distance, becoming tenuous as distance increases. Gen Y users of SNSs use popular dating sites, and the Chinese television program (subtitled in English), 'If you are the one', (Fei Cheng Wu Rao, JBSC) portrays such distance issues. Despite its entertainment contrivances, Fei Cheng Wu Rao highlights the problems when distance means compromising family and friends' face-to-face networks for potential marriage partners. The comfort of communication, too, is especially important in the Chinese tourism market, where potential tourists need seek familiarity [20]. The use of Electronic word-of- mouth, (E-wom) has allowed Chinese consumers (as tourists and travellers) to alternatively connect [33].

This is done on SNSs where information diffusion is a complicated convoluted process, attracting researchers from many different disciplines as Choe, Kim and Fesenmaier elaborate [34]. Factors that influence users of SNSs are more than curiosity [35]; in all aspects of consumer platforms, user-generated content (UGC) is influenced by myriad motivations [36] and from various social media sites [37].

\subsection{Diarising Travel in Social Media}

Diarising travel is a component of the tourism experience for sharing real-time experiences and recounting the past. No longer necessarily a hard-copy diary, the tourist gaze is now more likely to be online [38]. Travel diaries record location, current and past experiences, conversations, shared memories, and creates some degree of spatial awareness for the reader. This furthers shared participation, relationships, promoting participation in travellers' activities, and providing instantaneous information-sharing [39]. Travel diaries enable readers to learn from the experiences of many others [39] experiencing authentic or staged existential experiences [40]. Electronic word-of-mouth is becoming the digital alternative to disseminating advice, formerly provided from close relationships or from travel agents [41]. The potential tourist's enthusiasm is often buoyed by the travel experiences of others, and can potentially transfer into their own visiting actions [42]. 


\subsection{Information Diffusion in Tourism Research}

The literature of research in tourism and information diffusion can be seen from three broad perspectives:

(1) The influence of network structures. Examining a network structure is vital for understanding information diffusion, which determines the function of the network system and quality of information flow between network nodes. Baggio and Cooper [8] investigated the effect of a network structure on knowledge communication and transfer along a destination network using epidemic diffusion models. They found that a fragmented network may lead to a low capacity of a destination in absorbing knowledge and low speed of knowledge diffusion along a network. Therefore, in order to make a destination competitive, it is beneficial to form clusters of stakeholders. In 2014, Baggio later found links between a structured network and a tourism destination [11];

(2) The influence of nodes on a network. Individuals play different roles in distributing information along a social network. Yang and Leskovec [43] developed a linear influence model to predict how nodes influence each other and found that nodes (here, Twitter users) with the highest number of followers do not necessarily have the highest influence. The influence of individual nodes depends on the type of node and information. To date, there has been limited research done to understand the roles played by individuals in information diffusion along tourism social networks;

(3) Dynamic process or diffusion mechanism. The essential Vickrey-Clarke-Groves mechanism theory explores incentivising information diffusion through accurate social interaction to achieve socially-optimal outcomes and how information spreads along social networks [44]. It is used in ICT, linguistics, psychology, mathematics, statistics and tourism. Goffman's epidemic model [45] replicates infection between individuals, gradually diffusing, dispersing, losing its potency and eventually disappearing. A web forum's information diffusion provides an understanding of the forces behind the diffusion of ideas and is predictive. Epidemic-like, interest wanes and ends as the topic popularity loses interest within a web forum of dialogue. Four types of spatial diffusion processes were defined by Gould [46]: relocation diffusion, expansion diffusion, contagious diffusion and hierarchical diffusion. Although they were developed for spatial diffusion, they can be used for defining information diffusion.

\subsection{Information Diffusion, Online Review Helpfulness and Visiting Action Behaviour}

There is a need for alternative research perspectives into current global tourism and the influence of SNS, particularly of the dimensions of causal relationships between factor variables of demand and influence [47]. Three specific motivations for tourists seeking word-of-mouth are: convenience and quality, risk reduction and social reassurance [2]. Positive or negative online consumer reviews affect consumers' decision-making, pre-trip (planning), during-trip (considering alternatives) and post-trip (post-consumption behaviour) [48]. Huang, et al. [49] studied factors that contribute to the effectiveness of online reviews. Not only did they find that word count is a factor, but qualitative factors, such as review impact, reviewer experience, and reviewer cumulative helpfulness, also contribute to the usefulness of online reviews. They concluded that word count limit, however, had the biggest impact in terms of overall review efficacy, where the effect can then diminish or disappear. The characteristics of reviewers and review messages also have a certain degree of association with the effectiveness of online review advice. Qazi, et al. [50] discovered that review types and concepts affect review perceptions and helpfulness. Nonetheless, there are also lacunae in the predictive research around the understanding of the behaviours of the online travel community, most likely because of trip diary information diffusion. This is despite more than adequate data to assist in tourism design to better match the needs of tourists [22]. 


\subsection{System Theory and Tourism}

Tourism is a complex, adaptive, dynamic, chaotic, connected and nonlinear system [51,52] that connects and integrates individual components and creates a whole organism guided by principles and procedures. System theory [19], pioneered for tourism by Neil Leiper [53] allowed for the investigation of the myriad ontologies of components and structures for tourism destination management. Many theories have been developed to understand the dynamic nature of destination management, including the model of a tourist area cycle of evolution [51], chaos theory [54] and game theory [55]. Recently, network science has been called on to address the system [8,56], which people, goods and information that flow between tourism destinations, make such places viable and attractive.

Specific research of and understanding the motions (or perhaps 'touchpoints', as others define them [34]) within diarising travel in social media is the focus here in a specific tourism destination (WA) and one market (China). Tourist information diffusion along social media networks, tourist visiting action behaviour and tourism systems are observed in a temporal capacity. Using well-established business ecosystems as a model grounds this research. This background informs the theory being tested here, responding to the call that greater detail in research is required to "better understand traveller behaviours and experiences ... and how ... social media actually modify behaviours" [34].

\section{TIDE's Theoretical Framework}

\subsection{Theoretical Foundation of TIDE}

TIDE incorporates earlier research in information science, network science and tourism studies to understand the evolution of tourism information dissemination along social networks.

The TIDE system, partially based on the whole tourism system by Leiper [17], has two levels: a macro level and a micro level (See Figure 1). The tourism system at the macro level is made up of traveler-generating regions, traveller destination regions, departing and returning tourists and transit routes. The traveller-generating regions are the places where trips start and end. Tourists with various motivations to visit destination regions may return home with changed motivations and behaviours. The traveller destination regions receive tourists leading to interactions that influence tourists from socio-cultural, economic, technological and physical environment perspectives. Tourists can use different travel modes and routes to travel between origins and destinations, depending on their personal preference, availability and the convenience of the travelling supports. Thus, the tourist flow is a dynamic phenomenon. The movement of tourists between origins and destinations too, can change over time depending on:

- $\quad$ social and political interactions between origins and destinations;

- push factors driving tourists away from destinations, such as host counties' unemployment, a lack of services and amenities, epidemics, natural disasters or poverty;

- pull factors attracting tourists, such as potential employment opportunities, unique scenery, attractive climate, and communication technologies connecting people and places.

Tourism systems are open systems, which interact with external environments regularly from a human, socio-cultural, economic, technological, physical, political or legal perspective. Environments may impact a tourist system and also can be influenced by it.

TIDE is a part of the whole tourism systems at a micro level, which is a virtualised system. Tourists gain information, experience and emotions before, during and after their trips and bring them into a virtual world, that is, their social network, and then distribute this information, experience and emotion along social network services (SNSs). TIDE is primarily made up of SNS participants with varying degrees of participation. We have categorised these participants as influencers, close followers, loose followers and emotion sharers (see Figure 1):

- Influencers: trip diarists who have visited a destination and posted their experience and comments into their trip diaries. They may influence several types of followers; 
- Close followers: those who post comments and who have also visited the same destinations and post a trip diary of their own experience;

- Loose followers: those who post comments without providing evidence of visiting a destination;

- Emotion sharers: those who have travelled before reading any trip diary and then comment in a trip diary of their choice but not their own. They hold less persuasive inducement than the influencers.

Tourism information diffusion may or may not lead to outcomes such as a visiting action, which is defined as a trip to a diarised tourism destination. The interaction between influencers and close followers can result in visiting actions of close followers, while the interaction between influencers and emotion sharers and loose followers may or may not lead to a visiting action. However, when the travel or tourism activity is put into action, travellers may not only create an impact on the destination, but also encourage and motivate more travellers to begin to travel.

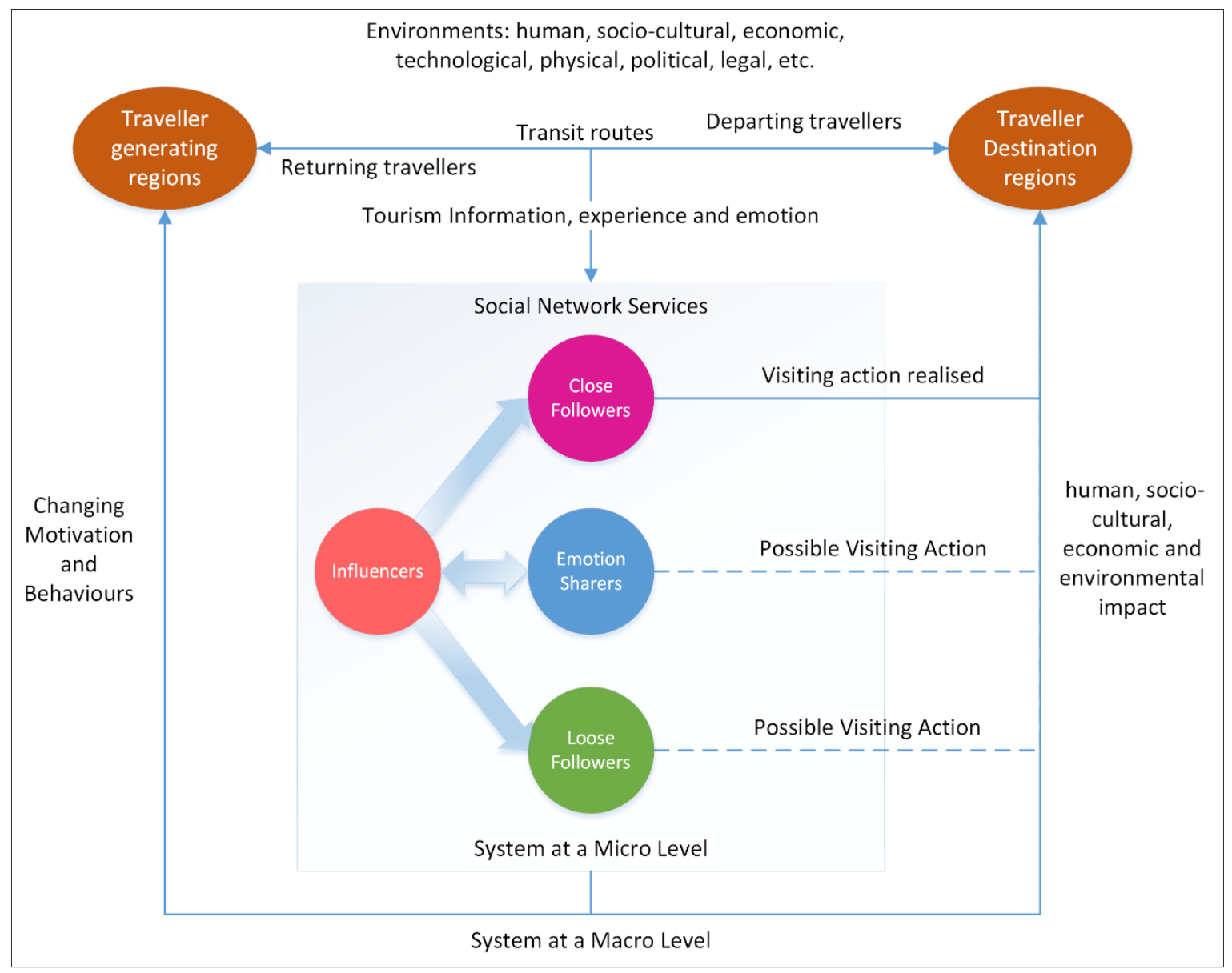

Figure 1. Tourism Information Diffusion Ecosystem (TIDE) details (adopted from [17,53]).

TIDE is also developed from information network science. It aims to further segregate the tourism information system into individual components, allowing a deeper understanding of the system, to explore the complex and directing components of interconnectivity, and to perceive the functioning of the 'whole'. It enhances and clarifies tourist behaviours.

\subsection{Definition of TIDE}

This section defines and illustrates the tourist information diffusion network system including its structure, process, function, and outcomes (See Figure 2). 


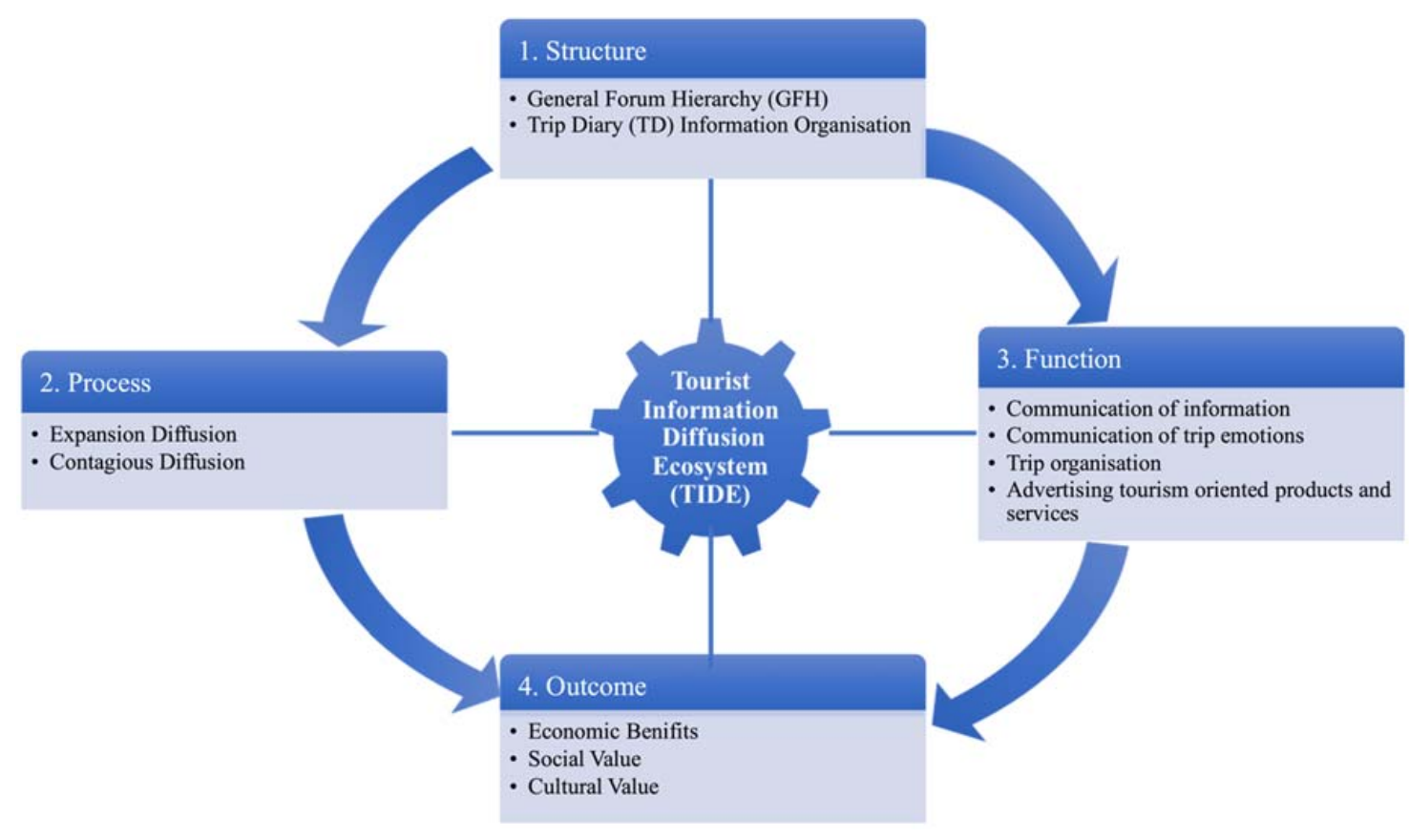

Figure 2. General organisation of the Tourism Information Diffusion Ecosystem.

\subsubsection{Structure}

This paper defines the structure of TIDE from two perspectives: general forum hierarchy structure (GFH) and trip diary (TD) information. General Forum structure was inspired by the Whole Tourism System [17,53] (See Figure 2). The General Forum Hierarchy contains threads, posts, trip comments and other tourist information, organised into a branch-like directory observed on websites such as Mafengwo.cn. The general forum contains categories, sub-categories, and threads leading to posts. Threads contain trip diary information, while posts contain comments. The trip diaries' information diffusion network structure can be organised into the following categories:

- Hierarchical structure: arranged by destination, styled on the real-world, or top-down categorisation for easy searching, of geographical location using continent, country, state, city, town, tourism attraction;

- Flat structure: a horizontally styled organisation of parallels, maintaining flexibility, organised by an individual or forum participant. Itncludes personal information, blogs, travel itineraries, destination information, local modes of travel, accommodation, restaurants and tourist attractions, and other related activities.

For trip diaries information diffusion network structure we use Naimzada's [57] ring, tree, star, mesh and hybrid networks for definition and categorisation, where information forms a:

- $\quad$ Ring network: passing from one participant to another, forming a circle;

- Tree network: passing from influencers to close followers, while close followers become influencers and pass trip diary information to other close followers to forming a tree-like structure;

- Star network: passing from influencers (hubs) to loose followers (spokes). The loose followers might not keep in contact;

- Mesh network: well-connected, communicative network, passing freely from or between influencers, close followers, loose followers and emotion sharers;

- Loosely connected network: passing intermittently from influencers, loose followers, and emotion sharers, with individual or pairs of users existing without communicating with others;

- Hybrid network: a combination of the above. 


\subsubsection{Processes of TIDE}

TIDE's expansion diffusion and contagious diffusion processes detail the various networks and relationships of tourism SNSs.

\section{Expansion Diffusion}

During the expansion diffusion process, influencers spread information and their travel experience of a tourist destination to followers, triggering the close followers' visiting actions to the destination. Expansion diffusion forms a chain of information-sharing networks. Within this network, the influencers are the major nodes of information distribution to all followers. Their followers may read, comment, or do both. The chain of reactions then evolves and expands close followers' roles, so they become higher-level participants or influencers themselves. This process is called close following. This means that after a close follower visits a destination, he or she posts his or her experience on a forum for sharing with others. As such, they then can become an influencer.

\section{Contagious Diffusion}

During the contagious diffusion process, information which is passed from influencers to loose followers shows little evidence of loose followers' visiting actions. Thus, this passive behaviour is categorised as a loose following process (see Figure 2). This indicates no travel to the destination so far. When emotion sharers post their travel experience, sharing this with influencers and other followers, but show no indication of destination return, this is termed as the emotion sharing process.

Therefore, contagious diffusion can be considered the potential to travel, whereas expansion diffusion is a definite action to travel. Expansion diffusion induces actions; contagious diffusion does not necessarily encourage action, just its potential.

\subsubsection{Functions of TIDE}

TIDE describes a tourism-users' ecosystem (real or virtual) in which SNS users communicate a range of information, feelings, thoughts and emotions, plan trips, and advertise tourism-oriented products and services. For example:

Information and Emotion Sharing (Self-Realisation and Self-Esteem of Travellers)

TIDE can reveal SNS users' self-realisation and self-esteem by sharing trip information, destinations and attractions, itinerary information, opportunities for creativity. Expressions of feelings, experiences, emotions and achievements are evaluated against and alongside other's trip comments [58], contributing to the popularity of the trip diaries and, in turn, boosting users' ranking on SNSs.

Travel Community-Interconnection and Integration of Places, Information, Travellers and Tourism Industries

TIDE allows SNS users to gain a sense of community and grow friendships through emotional connectedness. Tourism industries can connect to SNS users directly by advertising tourism-oriented products and services, and showcasing personal discoveries of good accommodation, restaurants, travel agencies, pricing, activities at attractions and airport transfers. Place (a physical world) and information (in a virtual world) are connected through information and knowledge diffusion along SNSs, decreasing the perception of distance between origin and destination through virtual space, which can boost local economics of the traveller-generating region.

Adaptation to the Environment (Dynamic Process)

The interactions between components of TIDE and interaction between its components outside of the TIDE environment are also dynamic. Influencers can continue adding new trip diaries; their followers and/or their own influencers, can answer questions, facilitate their trip organisation and 
share their comments, therefore elevating their SNS status. This knowledge transfer process can be contagious. Influencers change their motivation and behaviours with actual travel, posting their values online. As well, destinations may be impacted socially, culturally, economically or environmentally by visitors in positive or negative contexts. Constant interaction and interconnection between users, make TIDE evolve, grow or decline. The use of digital devices immediately makes a user a mass sharer of tourism information, of the meaningful self-disclosure of experiences, emotions and valuable tourism experiences. This is a recycling of the cultural construction of the touristic experience [59]; so to avoid malfunction, a system of management and controls must be implemented.

\subsubsection{Outcomes of TIDE}

TIDE is a regenerative and sustainable platform due to the effects of the expansion and contagious information diffusion process. This research summarises the evolution of TIDE from an economic, social and cultural perspective.

- Economic: increased exposure to tourist information through SNSs, which leads to potential tourism and encourage spending at a tourist destination;

- Social: effective channels to make new friends internationally, encourage tourists' positive feelings and attitudes and lift travel experiences to endure through recall and memories and recollect tourism memories;

- Cultural value: better knowledge of the culture and expectations of the destination and its communities. A destination that satisfies tourists is well-recommended by the tourists though pictures, description, comments and feedback of the destination on SNSs, which defines the destination's image and influences other tourists' purchasing decisions [60].

This briefly defines the structure, process, function and outcome of TIDE. The tourism system, at the micro level is a complex and dynamic virtual system, but which is closely connected to the tourism system at the macro level—or the real physical tourism system. In the following sections, a case study has been used to partially implement TIDE and provide evidence to further understand the conceptual model.

\section{Methodology}

This section introduces the case study in Western Australia (WA) where some components of the TIDE have been implemented. In-depth tourist information diffusion network analysis has been conducted based on the TIDE framework, using the Chinese website Mafengwo.cn, with a focus on WA's tourist destinations. A discussion follows on the study area, the data collection methods, the information diffusion network analysis, and the modelling of visiting actions of close followers to WA tourist destinations.

\subsection{Study Area}

Australia's vast and 'dramatic, physical landscape' [61] is exemplified by WA. It has Australia's fourth largest population, currently 2,558,951 but it is declining due to an economic downturn in, and restructuring of, its mining industry. In 2017, the state's $252,644,623 \mathrm{~km}^{2}$ had a population density of 1 person per $\mathrm{km}^{2}$, in 2019, it was 0.89 persons per $\mathrm{km}^{2}$ [62]. Approximately $86 \%$ of the population lives in the Greater Metropolitan Area of Perth, $641,786 \mathrm{~km}^{2}$ with 317.7 persons per $\mathrm{km}^{2}$ [63] (see Figure 3).

In the year ending September 2018, the total number of intrastate visitors to WA increased by $8.8 \%$ to 1.5 million visitors [64], while international visits to WA had increased by $0.6 \%$ to 954,800 , with Chinese visitor numbers increasing by $0.4 \%$ to 57,200 . These Chinese visitors were the top spenders in WA, contributing $\$ 271$ million to the local economy [65]. To attract more Chinese tourists, the WA government has committed AUD $\$ 1$ million to an advertising campaign to promote the state in Shanghai [66]. 


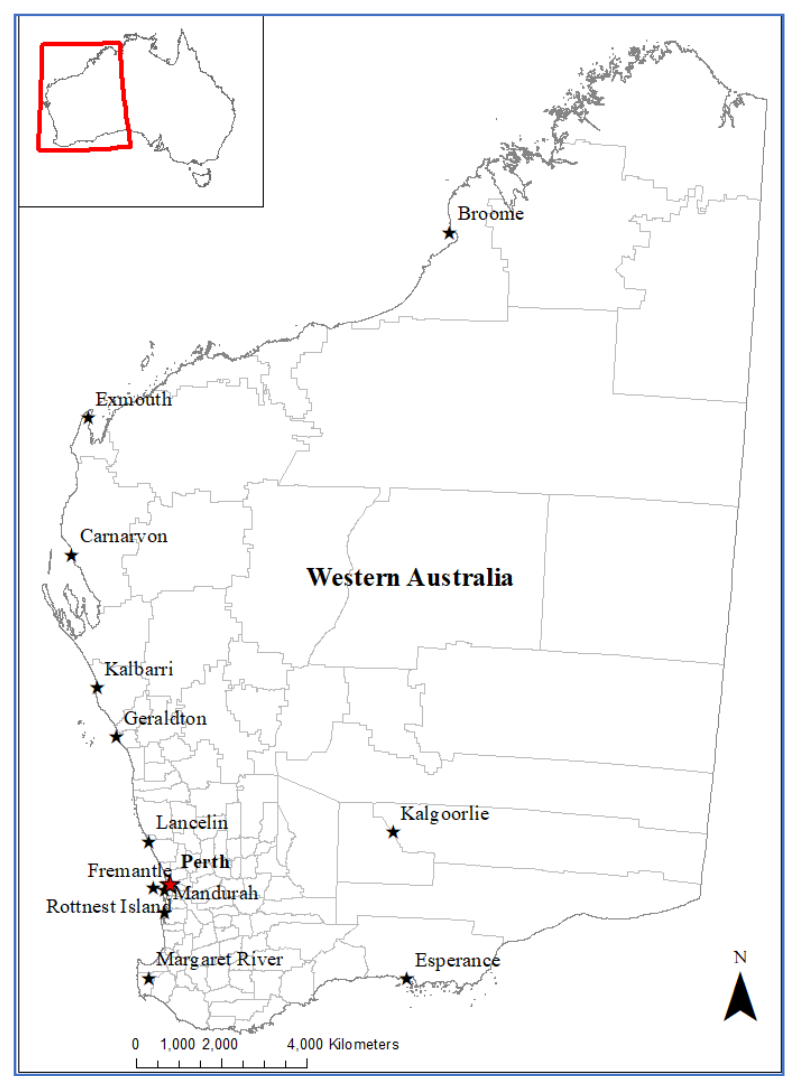

Figure 3. Map of Western Australia (Source: authors' own, created by ArcGIS).

\subsection{Data Collection Methods}

This research ran screen-scraping software over the major Chinese-language travel experience website Mafengwo.cn to capture a database of trip diaries along with the comments and responses of the travellers and their followers. The information was anonymous due to the website's embedded privacy and security precautions.

We obtained a total of 328 trip diaries covering the period 1 January 2009 to 12 September 2017. Most were written for specific destinations (Perth (265), Margaret River (9), Kalbarri (5), Fremantle (3), Rottnest Island (2), Broome (1), Exmouth (1), Carnarvon (1), Geraldton (1), Lancelin (1), Mandurah (1), Esperance (1), Kalgoorlie (1)). Another 36 trip diaries have been categorised under WA.

\subsection{Tourism Information Diffusion Network Analysis}

An analysis was conducted of the Mafengwo.cn characteristics of information diffusion networks as a result of the close following, loose following and emotion sharing processes. These characteristics include the number of nodes and edges, average degree, average shortest path and centralisation of information diffusion networks. The information diffusion network was then visualised.

For this study, SNS participants are represented as nodes. The information flowing between these nodes are marked as the edges of a network. In the close following network, influencers and close followers are marked as nodes, the information passing from influencers to nodes is marked as edges.

The first network analysis is the identification of the important nodes in the network. Degree centrality was introduced to measure the centrality of an individual SNS contributor regarding the number of nodes to which a particular node connects. In the context of the directed network, out-degree centrality is more meaningful and is defined as:

$$
C_{i, o u t}=\sum_{j=1}^{n} \boldsymbol{I}_{i j}
$$


where $\boldsymbol{I}_{i j}$ denotes one of the outward connections from node $i$ to node $j$, and $n$ indicates the number of nodes within the network. Out-degree centrality of a node $i$ is the sum of the numbers of nodes $j$ in that network which connect outwards, i.e. the number of close followers in a close following network.

The second measure of the network characteristics is the geodesic distance, defined as the length of the shortest path between two nodes. In the directed information diffusion network, this indicator is used to evaluate the diffusion distance along the network, and on average how fast the information spreads along the network.

The third measure of the network characteristics is the network centralisation, which is used to understand how equal are the nodes. It calculates the centrality scores among nodes in the network. The network centralisation $C_{D}$ is defined as [67]:

$$
C_{D}=\frac{\sum_{i=1}^{n}\left(C_{\max }-C_{i}\right)}{(n-1)(n-2)}
$$

where $C_{\max }$ is the max out-degree centrality among all the nodes within a network, $C_{i}$ is the out-degree centrality of node $I$, and $n$ is the total number of nodes within the information diffusion network.

\subsection{Modelling: Zero-Inflated Poisson (Zip) Model for Predicting Visiting Actions to Tourist Destinations Due to Tourism Information Diffusion}

This study used a zero-inflated Poisson (ZIP) model to understand what factors affect the number of visiting actions to tourist destinations by close followers through information sharing between influencers and followers. The number of close followers of each influencer acts as a proxy for visiting actions to tourist destinations, because close followers not only comment on the trip diary of destinations but, importantly, also mention their own visiting actions in the trip diary. Because not all influencers have close followers, and the number of close followers for each influencer may display over-dispersion and excess zeros, we adopted the zero-inflated Poisson (ZIP) regression model to predict the number of visiting actions to tourist destinations by close followers [68-71]. The ZIP model employed two separate models, a Poisson count model for predicting count values and the logit model for predicting excess zeros. We used the pscl package in R version 3.4.1 [72,73] to run the ZIP model, which included the following common features of SNSs:

- Influencer's accumulative efforts devoted to the SNS, such as time, the number of information diffusion posted, the number of times answering other people's questions on SNSs, quantified as rank;

- Number of followers of the influencer who will view the influencer's trip diary first, marked as fans;

- Number of words included in the trip diaries, marked as word;

- Number of pictures included in the trip diaries, marked as picture;

- Times of the trip diaries viewed, marked as view;

- Times of the trip diaries saved, marked as save;

- Times of the trip diary was placed on the top by SNS users, marked as placing on the top;

- Times of the trip diaries shared, marked as share;

- Duration since trip diaries first posted until 12 September 2017, marked as duration.

In ZIP regression, the number of close followers, $\mathbf{Y}=\left(Y_{1}, \ldots, Y_{n}\right)^{\prime}$ are independent and

$$
\begin{gathered}
Y_{i} \sim 0 \quad \text { with probability } p_{i} \\
\sim \operatorname{Poisson}\left(\lambda_{i}\right) \text { with probability } 1-p_{i} \\
\operatorname{Pr} .\left[Y_{\mathrm{i}}=0\right]=p_{i}+\left(1-p_{i}\right) e^{-\lambda_{i}}
\end{gathered}
$$




$$
\operatorname{Pr} .\left[\mathrm{Y}_{\mathrm{i}} \geq 1\right]=\left(1-p_{i}\right) \frac{\lambda_{i}^{k} e^{-\lambda_{i}}}{k !}, k=1,2,3, \cdots
$$

Moreover, the parameters $\boldsymbol{\lambda}=\left(\lambda_{1}, \cdots, \lambda_{\mathrm{n}}\right)^{\prime}$ and $\mathbf{p}=\left(p_{1}, \cdots, p_{\mathrm{n}}\right)^{\prime}$ satisfy

$$
\begin{gathered}
\ln \left(\lambda_{i}\right)=\mathbf{B} \boldsymbol{\beta} \\
\operatorname{logit}(\mathbf{p})=\log \left(\frac{\mathbf{p}}{1-\mathbf{p}}\right)=\mathbf{G} \gamma
\end{gathered}
$$

Here, $\mathbf{B}$ and $\mathbf{G}$ are covariate matrices. Before running the model, we also checked the correlation between these factors to ensure that we included variables independent to each other.

\section{Results}

\subsection{The Characteristics of the Information Diffusion Networks}

A collection was conducted of 328 trip diaries written by 219 influencers who had 1326 commenters (close followers, loose followers, and emotion sharers). Importantly, 181 commenters (close followers, emotion sharers) eventually travelled to WA 187 times. The expansion diffusion process contains 229 diffusion links (See Table 1), connecting 100 influencers and 133 close followers. In contrast, the contagious diffusion has two types of processes: the first process is loose following, composed of 198 influencers and 1141 loose followers with 1425 diffusion links. The second process is emotion

\begin{tabular}{|c|c|c|c|c|c|c|}
\hline \multicolumn{2}{|c|}{ Type of Diffusion Process } & $\begin{array}{c}\text { No. of } \\
\text { Diffusion Links }\end{array}$ & $\begin{array}{c}\text { No. of } \\
\text { Influencers }\end{array}$ & $\begin{array}{l}\text { No. of Close } \\
\text { Followers }\end{array}$ & $\begin{array}{l}\text { No. of Loose } \\
\text { Followers }\end{array}$ & $\begin{array}{c}\text { No. of Emotion } \\
\text { Sharers }\end{array}$ \\
\hline \multicolumn{2}{|c|}{ Expansion Diffusion (close following) } & 229 & 100 & 133 & l & I \\
\hline \multirow{2}{*}{$\begin{array}{l}\text { Contagious } \\
\text { Diffusion }\end{array}$} & Loose following & 1425 & 198 & l & 1141 & \\
\hline & Emotion sharing & 65 & 49 & l & l & 55 \\
\hline
\end{tabular}
sharing, composed of 49 influencers and 55 emotion sharers and contains 65 diffusion links.

Table 1. Two types of diffusion processes.

\subsection{The Structure of Their Information Diffusion Network}

Figures 4 and 5 graphically illustrate the networks of expansion diffusion and contagious diffusion. The nodes in the networks represent the users of the tourism SNSs. A set of edges between pairs of nodes represent the directional information diffusion process between different users. The expansion diffusion network appears more connected than the contagious diffusion networks, revealed as a tree network (see Figure 4).

In the loose following network, influencers dominated the network and loose followers seldom communicated to each other, which created a star network (only displaying influencers and their loose followers with a degree greater than 30) (see Figure 5).

In contrast, influencers and emotion sharers are loosely connected in the emotion sharing network. Pairs of influencers and emotion sharers connect occasionally (see Figure 6). 


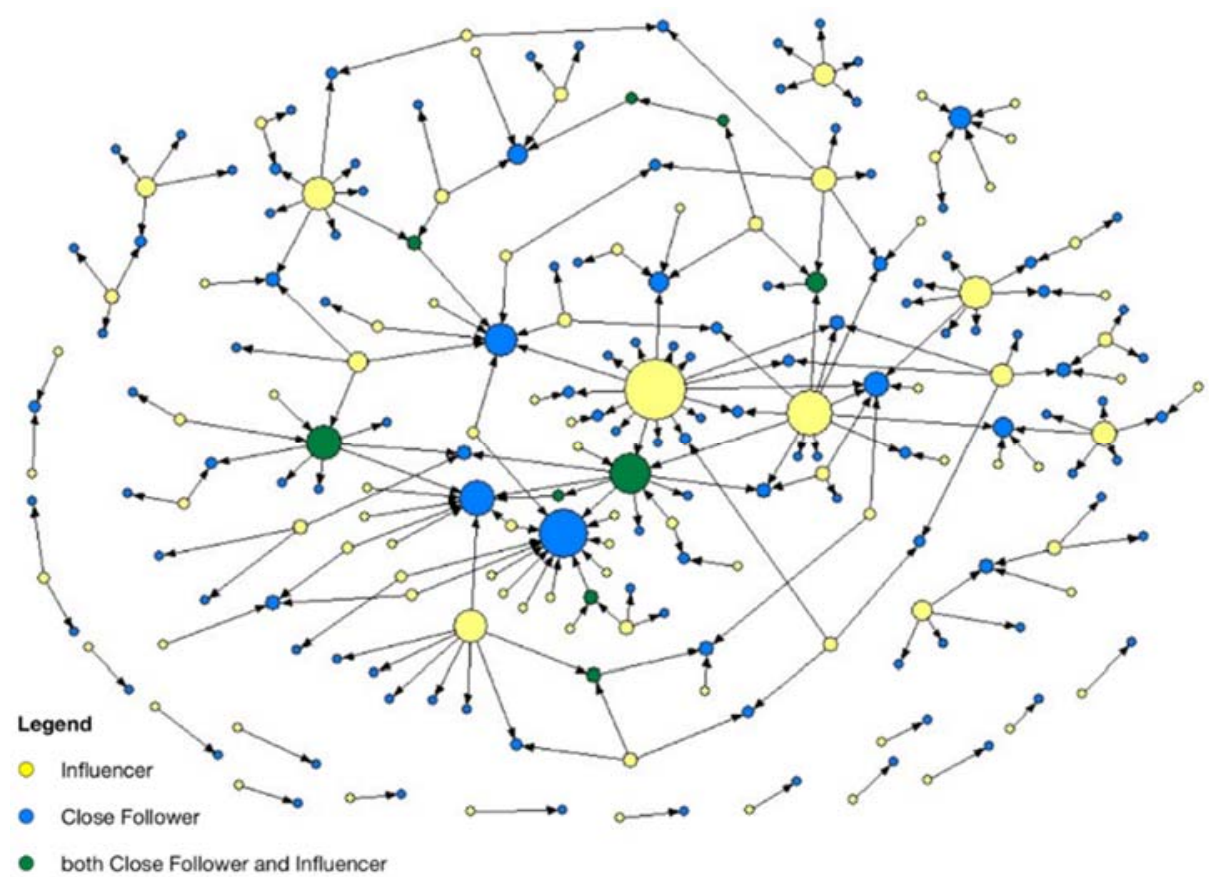

Figure 4. Graph of expansion diffusion network in a tree network between influencers and close followers.

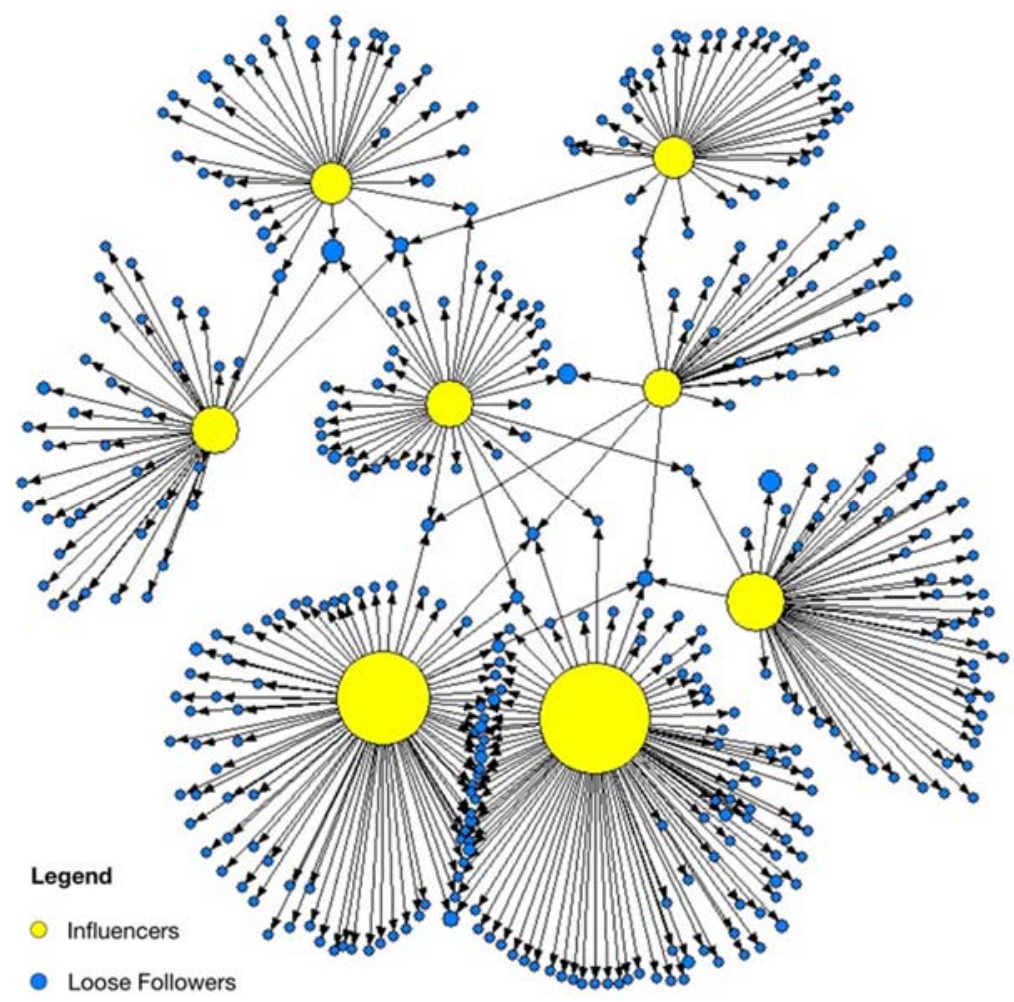

Figure 5. Graph of contagious diffusion. 


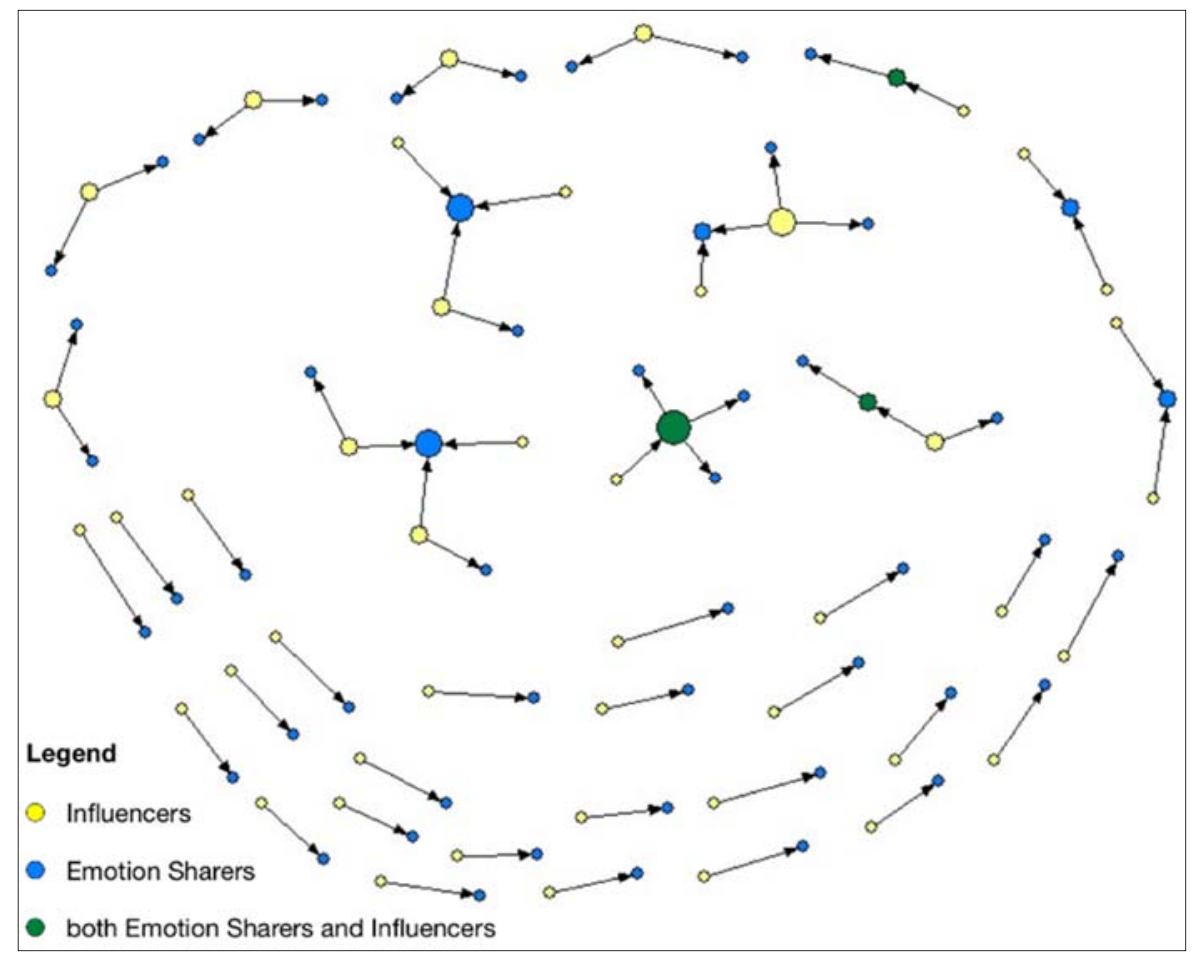

Figure 6. The network of emotion sharing between a trip diary author and its commenters, the emotion sharers.

Some simple network statistics over these three networks, such as the number of nodes and edges, are displayed below in Table 2. The size of the network of loose following is much larger than either of the close following or emotion sharing networks.

Table 2. Results and analysis of network characteristics.

\begin{tabular}{cccc}
\hline & \multicolumn{3}{c}{ Network } \\
\cline { 2 - 4 } & Close Following & Loose Following & Emotion Sharing \\
\hline Number of Nodes & 224 & 1,339 & 101 \\
Number of Edges & 229 & 1,425 & 65 \\
Average degree & 2.027 & 2.128 & 1.228 \\
Average shortest path & 1.204 & 1 & 1.075 \\
Network centralisation & 0.072 & 0.077 & 0.0283 \\
\hline
\end{tabular}

To calculate the characteristics of each of these three networks (the average degree, average shortest path and network centralisation), we used UCINet 6.216 [74]. The average degree of the close following network, the loose following network and emotion sharing network are 2.027, 2.128 and 1.228, respectively. This means that, on average, each influencer has 2.027 close followers, 2.128 loose followers and 1.228 emotion sharers.

The average shortest path indicates the efficiency of the information diffusion network. The average shortest path of the close following network, the loose following network and emotion sharing network is $1.204,1$ and 1.075 respectively, indicating that information diffusion through the close following network has a longer-than-average shortest path compared to that of the loose following and emotion sharing networks.

The network centralisation of the close following network, the loose following network and the emotion sharing network are $0.072,0.077$ and 0.0283 separately, indicating that the influencers played more significant roles in the close following and loose following networks, compared to that within the emotion sharing network. We conducted a detailed analysis for close following networks because close followers are most likely to travel and to record in the trip diary. 


\subsection{Information Diffusion Process for Close Followers}

The relationship was plotted between the number of close followers and the duration of the trip diaries' diffusion from influencers to close followers. The duration of trip diary diffusion starts from when the trip diary was posted to when close followers arrived at their destinations in WA (see Figure 7). It reveals a power law relationship between these two variables. This means that the number of close followers varies inversely with trip diary diffusion time.

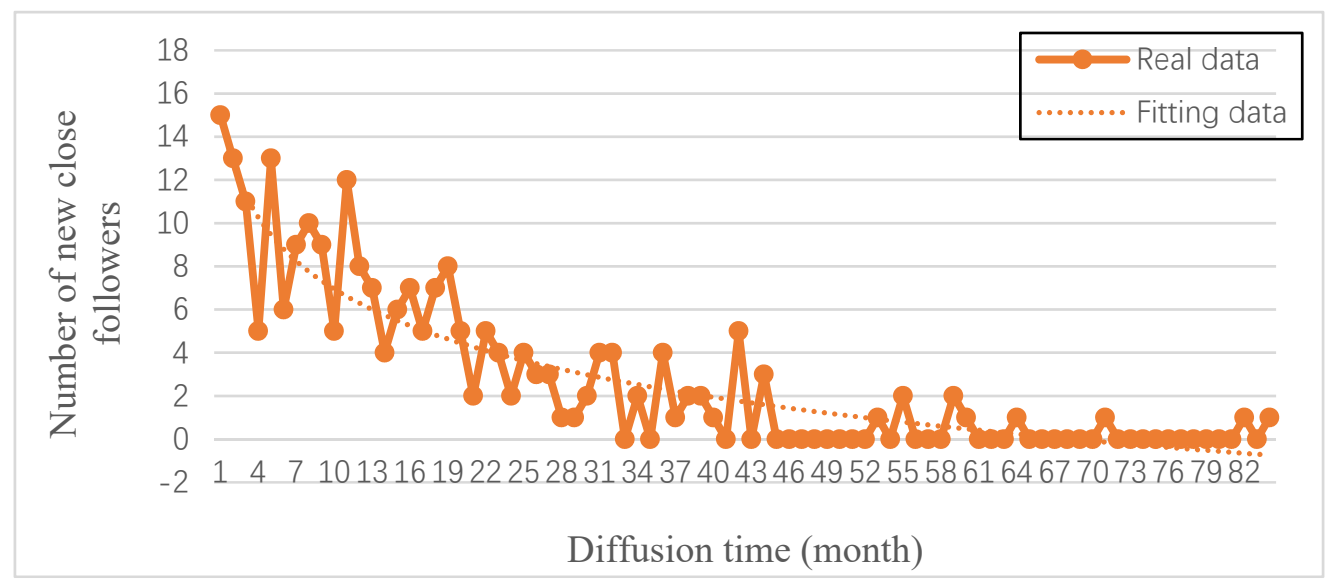

Figure 7. The relationship between the number of new close followers and the duration of trip diaries' diffusion.

We also investigated the number of new trip diaries and new close followers who read trip diaries and also visited WA each year between January 2009 and September 2017. In Table 3, the rows illustrate the number of new trip diaries for each year, while the columns show the number of new close followers for each subsequent year after the trip diaries were published.

In 2013, 12 trip diaries were detected from the network, and in the subsequent 365 days (year 0), 18 close followers commented on the trip diaries. In years 1-4, the number of close followers decreased to 0 . Similarly, in 2014, 14 trip diaries were posted with 15 close followers detected in year 0, or 2014, rapidly decreasing to 5 close followers in 2016. However, we found 4 close followers in the partial year of 2017. While 2011 trip diaries showed an increase in close followers compared to Year 2, by Year 5 the number of close followers also decreased to 1 . The highest number of trip diaries was in 2016, numbering 32, with also the highest close followers to 29, but these fell off to 9 in the partial data collection of Year 1 (2017). From the time that the trip diaries were posted between 2013 and 2016, they attracted a significant number of close followers and then just as rapidly, they decreased in the subsequent years. The close follower numbers, which have yet to be collected, are expected to present more interesting findings. 
Table 3. The number of new close followers since trip diaries posted between January 2009 and September 2017.

\begin{tabular}{|c|c|c|c|c|c|c|c|c|c|c|}
\hline \multirow{3}{*}{$\begin{array}{l}\text { Year (No. of New } \\
\text { Trip Diaries) }\end{array}$} & \multicolumn{9}{|c|}{ The Number of New Close Followers since Trip Diaries have Been Posted } & \multirow{3}{*}{$\begin{array}{l}\text { Total New Close } \\
\text { Followers }\end{array}$} \\
\hline & Year 0 & Year 1 & Year 2 & Year 3 & Year 4 & Year 5 & Year 6 & Year 7 & Year 8 & \\
\hline & (1-365 days) & $(366-730)$ & (731-1095) & $(1096-1460)$ & $(1461-1825)$ & $(1826-2190)$ & (2191-2555) & $(2556-2920)$ & (2920-3285) & \\
\hline 2009 (trip diary 2) & 0 & 0 & 1 & 1 & 2 & 1 & 2 & 1 & 0 * & 8 \\
\hline 2010 (trip diary 2) & 0 & 0 & 0 & 1 & 2 & 0 & 0 & 0 * & & 3 \\
\hline 2011 (trip diary 3) & 1 & 4 & 9 & 1 & 2 & 1 & 0 * & & & 18 \\
\hline 2012 (trip diary 7) & 3 & 8 & 3 & 2 & 0 & $0 *$ & & & & 16 \\
\hline 2013 (trip diary 12) & 18 & 6 & 3 & 4 & 0 * & & & & & 31 \\
\hline 2014 (trip diary 14) & 15 & 10 & 5 & $4 *$ & & & & & & 34 \\
\hline 2015 (trip diary 14) & 10 & 7 & $2 *$ & & & & & & & 19 \\
\hline 2016 (trip diary 32) & 29 & $9 *$ & & & & & & & & 38 \\
\hline 2017 (trip diary 17) & $13 *$ & & & & & & & & & 13 \\
\hline
\end{tabular}

${ }^{*}$ The data collected up until September 2017 


\subsection{ZIP Regression Model of Visiting Action to Tourist Destinations}

A ZIP model was developed for understanding factors affecting the visiting actions of close followers to tourist destinations in WA (see Table 4). For the Poisson regression model, the number of times an influencer's trip diary was saved by other users, the number of times trip diaries were placed on the site's top ranking of influence, the log of the number of pictures in trip diaries, and the $\log$ of trip duration were found to be statistically significant in influencing the total amount of close followers connected to each influencer. The first two of these factors have a weak positive impact on diffusion effects $\left(\alpha_{1}=\exp (0.0055)=1.0055\right.$ and $\mathrm{p}=0.000<0.05$ and $\alpha_{2}=\exp (0.0012)=1.0012$ and $p=0.015<0.05)$. The log of duration and log of picture numbers have a stronger positive impact on diffusion effects $\left(\alpha_{4}=\exp (0.4564)=1.5784\right.$ and $\mathrm{p}=0.000<0.05$ and $\alpha_{5}=\exp (0.2215)=1.2479$ and $p=0.006<0.05)$. Rank also has a weak positive impact on diffusion effects $\left(\alpha_{3}=\exp (0.0177)=1.0179\right.$ and $\mathrm{p}=0.0143<0.05)$.

Table 4. Results of zero-inflated Poisson (ZIP) model $(\mathrm{n}=274)$.

\begin{tabular}{llll}
\hline \multicolumn{4}{c}{ ZIP Model (Diffusion Effects) } \\
\hline Poisson Regression & \multicolumn{1}{c}{ Zodel Part } & Zero-Inflation Model \\
\hline Parameter & Estimate (SE) & Parameter & Estimate (SE) \\
\hline (Intercept) & $-3.9193\left(1.94 \times 10^{-5}\right)^{* * *}$ & $($ Intercept $)$ & $3.0704(0.0134)^{*}$ \\
Save & $0.0055\left(2.01 \times 10^{-9}\right)^{* * *}$ & save & $-0.0366(0.0017)^{* *}$ \\
Placing on the top & $0.0012(0.015)^{*}$ & Ln_duration & $-0.4085(0.0304)^{*}$ \\
Rank & $0.0177(0.0143)^{*}$ & & \\
Ln_duration & $0.4564\left(9.60 \times 10^{-6}\right)^{* * *}$ & & \\
Ln_picture & $0.2215(0.0063)^{* *}$ & & \\
\hline Log-likelihood & -351.4 on $12 \mathrm{Df}$ & & \\
chi-squared test & $1.417239 \times 10^{-48}(\mathrm{df}=12)$ & & \\
Zero observations & 157 & & \\
\hline
\end{tabular}

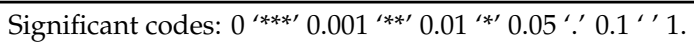

For the zero-inflated Poisson model, the significant predictor of there being zero close followers of influencers are the number of times trip diaries were saved and the log of duration since the trip diary was first posted. The higher the number of trip diaries that were saved and the longer the posted trip diaries remained online, the fewer predicted zero followers of each influencer.

\section{Discussion and Conclusions: The Implication of TIDE and Its Future Uses}

This study developed a new theoretical framework, named Tourism Information Diffusion Ecosystem (TIDE), in order to understand the diffusion of tourist information along SNSs. We have so far partially implemented TIDE using a case study of Mafengwo.cn, a Chinese, user-generated social network website to explore tourist SNSs relationships and their likelihood to influence travel decisions to Western Australia.

From the initial trip diaries' postings, the research discovered changes in the number of new close followers. Therefore, three phases were used: initial stage, development stage and widely accepted stage. In the initial stage (2009 to 2010, our case study 2009 to 2017), there were few website users and the trip diaries' impact was very limited. During the development stage, more website users participated in online communications. The number of close followers increased in the first two years, then declined in the following years. This pattern is similar to the change of innovation collaboration network; the bell curve [75]. The period of 2011-2012 demonstrates this pattern.

The widely accepted stage follows the pattern found in news media diffusion [76], where the pattern indicates readership spikes when fresh information is first disseminated. It rapidly diminishes as reader interest, too, declines. This is also evident in this case study where new trip diaries are more likely to have close followers' attention; with participant numbers falling off rapidly over the following 
year. This pattern follows a power law distribution [77]. Our case study evidence shows that close followers are mostly influenced by trip diaries in the first two years. This finding strongly suggests that tour operators and providers need to consider incorporating in one- or two-year cycles for their marketing strategies through online platforms at this widely accepted stage within the network.

Tourism policies can significantly influence tourism demand. The study for 2013 was in a period of political change. The Chinese government's policies for national outbound tourism relaxed visa restrictions for Chinese people travelling overseas [78,79]. Together with the rise of the Chinese Renminbi, this induced a spike in close-follower node communication along the website of Mafengwo.cn. Conversely, past policy alterations can have the potential to affect international relations, rapidly resulting in restrictions and travel bans, and redirecting tourists to other destinations.

In this study, the specific behaviours of close followers, loose followers and emotion sharers have been observed. The close following network was the most communicative and connected network, whereas the latter two were the least likely to communicate. This finding also suggests that the tourism industry needs to encourage greater communication between loose followers and emotion sharers in order to initiate future visiting actions (travel). Clever marketing strategies need to be used here to highlight common interests, to encourage loose followers to behave more like close followers, and to evolve into consumers and tourists.

This study reflects the small-world effect of the average shortest path first identified by Shirky [80], despite the loose following network being the largest compared to the other two network relationships. Our study's loose follower network had a star shape; influencers, as acquaintances in the loose following network, played more crucial roles in connecting loose followers than in the other two networks. The larger the social network in a small world network, the more important the role of the highly connected nodes are in linking others within the network [80]. Our study produced interesting findings-factors which influenced online tourist behaviour, with the potential to convert this into touristic behaviour or visiting actions.

The analogy that a 'picture is worth a thousand words' is echoed here. Trip diaries with a high percentage of photographs attracted more followers to influencers. Additionally, the longer the publication period of a trip diary, the higher the ratio of followers to influencer. These evaluative findings here are fundamentally important and reveal behavioural connections. The effect of time on relationships between the number of new trip diaries, new close followers (who read trip diaries), and those who had also visited WA, revealed that trip diaries are strategically more influential during the first two years after diary publication. Any cursory glance will indicate that tourism organisations use travel websites for destination marketing. Our study suggests that the frequent use of 'real' pictures in a new trip diary plays an crucial role in influencing readers' travel decision-making. This study highlights the importance of these variables, the criteria of which determine the rank (and role) of influencers in ongoing updates in the management of travel websites.

TIDE is a regenerative and sustainable system of variable, dynamic, diverse and interconnected characteristics. This study defined the basic components of the TIDE: structure, process, function, and outcome. This research investigated two components of TIDE, the structure and the process, using a small dataset from the website of Mafengwo.cn. Other specific details of TIDE have yet to be discussed and tested, but initial results prove that this is a sound theoretical model that warrants further research. Such areas include defining other information diffusion processes or network structures based on other typologies-for example, by the type of information processedand alternative dissemination choices, such as other websites. Other yet-to-be-identified activities also include indicators for the demographics and future preferences of tourists. Wang and Fesenmaier [81] concluded that travel agencies now play smaller roles in encouraging visiting actions in an online community; this study has confirmed their conclusion. Further studies using other destinations, such as the eastern states in Australia, are expected to add a deeper perspective to this theoretical framework.

Author Contributions: Conceptualization, T.L., J.X. and L.C.-D.; methodology, T.L., J.X. and L.C.-D.; software, T.L.; validation, J.X. and L.C.-D.; formal analysis, T.L.; investigation, L.C.-D. and J.X.; resources, T.L., J.X. and 
L.C.-D.; data curation, T.L.; writing-original draft, T.L., J.X. and L.C.-D.; writing—review and editing, T.L., J.X. and L.C.-D.; visualization, T.L. and J.X.; supervision, J.X.; project administration, J.X.; funding acquisition, T.L. All authors have read and agreed to the published version of the manuscript.

Funding: This research was supported by China Scholarship Council under Grant No. 201608330349.

Acknowledgments: The authors would like to thank of Mafengwo.cn for providing data for the study. We are very grateful to Bankwest Curtin Economics Centre for providing financial support for the study. Special thanks is given to Professor Arch Woodside for contributing suggestions for improving the paper. The views expressed in this article are those of the authors, and do not necessarily reflect the views of any organisation.

Conflicts of Interest: The authors declare no conflict of interest. The funders had no role in the design of the study; in the collection, analyses, or interpretation of data; in the writing of the manuscript, or in the decision to publish the results.

\section{References}

1. Leung, D.; Law, R.; van Hoof, H.; Buhalis, D. Social Media in Tourism and Hospitality: A Literature Review. J. Travel Tour. Mark. 2013, 30, 3-22. [CrossRef]

2. Kim, H.; Xiang, Z.; Fesenmaier, D.R. Use of The Internet for Trip Planning: A Generational Analysis. J. Travel Tour. Mark. 2015, 32, 276-289. [CrossRef]

3. Hlee, S.; Cheng, A.; Koo, C.; Kim, T. The difference of information diffusion for Seoul tourism destination according to user certification on Sina Weibo: Through data crawling method. Int. J. Tour. Sci. 2017, 17, 262-275. [CrossRef]

4. Chua, M.W.J. Diffusion of Travel Information through Innovation: A Social Network Analysis; The University of Queensland: Brisbane, Australia, 2012.

5. Baggio, R.; Del Chiappa, G. Real and virtual relationships in tourism digital ecosystems. Inf. Technol. Tour. 2014, 14, 3-19. [CrossRef]

6. Miguéns, J.; Baggio, R.; Costa, C. Social media and tourism destinations: TripAdvisor case study. Adv. Tour. Res. 2008, 26, 1-6.

7. Dhaigude, A.S.; Kapoor, R.; Ambekar, S. A conceptual model for adoption of information communication technology in the travel and tourism industry. Tour. Recreat. Res. 2016, 41, 49-59. [CrossRef]

8. Baggio, R.; Cooper, C. Knowledge transfer in a tourism destination: The effects of a network structure. Serv. Ind. J. 2010, 30, 1757-1771. [CrossRef]

9. Baggio, R. Collaboration and cooperation in a tourism destination: A network science approach. Curr. Issues Tour. 2011, 14, 183-189. [CrossRef]

10. Beritelli, P. Cooperation among prominent actors in a tourist destination. Ann. Tour. Res. 2011, 38, 607-629. [CrossRef]

11. Baggio, R. Creativity and the Structure of Tourism Destination Networks. Int. J. Tour. Sci. 2014, 14, 137-154. [CrossRef]

12. Hsiao, J.P.-H.; Jaw, C.; Huan, T.-C. Information diffusion and new product consumption: A bass model application to tourism facility management. J. Bus. Res. 2009, 62, 690-697. [CrossRef]

13. González, S. Bilbao and Barcelona 'in motion'. How urban regeneration 'models' travel and mutate in the global flows of policy tourism. Urban Stud. 2011, 48, 1397-1418. [CrossRef]

14. Racherla, P.; Hu, C. A social network perspective of tourism research collaborations. Ann. Tour. Res. 2010, 37, 1012-1034. [CrossRef]

15. Bakshy, E.; Rosenn, I.; Marlow, C.; Adamic, L. The role of social networks in information diffusion. In Proceedings of the 21st International Conference on World Wide Web, Lyon, France, 16-20 Apirl 2012; ACM: New York, NY, USA, 2012; pp. 519-528.

16. Baggio, R.; Scott, N.; Cooper, C. Improving tourism destination governance: A complexity science approach. Tour. Rev. 2010, 65, 51-60. [CrossRef]

17. Leiper, N. Tourist attraction systems. Ann. Tour. Res. 1990, 17, 367-384. [CrossRef]

18. Iansiti, M.; Levien, R. The Keystone Advantage: What the New Dynamics of Business Ecosystems Mean for Strategy, Innovation, and Sustainability; Harvard Business Press: Boston, MA, USA, 2004.

19. Von Bertalanffy, L. General System Theory; Penguin, Braziller: Middlesex, UK, 1968. 
20. Xia, J.C.; Adriano, R.; Prude Carcausto Zea, Z.; Crowe-Delaney, L.; Liu, Y.; Holmes, K.; Chen, Z. Are We China-Ready? Chinese Tourism in Western Australia. 2018. Available online: https: //bcec.edu.au/publications/are-we-china-ready/ (accessed on 16 December 2019).

21. Crowe-Delaney, L. Queensland-Gold Coast tourism, the Japanese era 1980-1997 and single market strategies-a case study. In Ethical and Responsible Tourism: Managing Sustainability in Local Tourism Destinations; CRC Press, Taylor Francis, Routledge Earthscan: Boca Raton, FL, USA, 2019.

22. Xiang, Z.; Fesenmaier, D.R. Big data analytics, tourism design and smart tourism. In Analytics in Smart Tourism Design; Springer: Berlin/Heidelberg, Germany, 2017; pp. 299-307.

23. Hall, C.M. Framing behavioural approaches to understanding and governing sustainable tourism consumption: Beyond neoliberalism, "nudging" and "green growth"? J. Sustain. Tour. 2013, 21, 1091-1109. [CrossRef]

24. Saarinen, J.; Rogerson, C.M.; Hall, C.M. Geographies of Tourism Development and Planning; Taylor \& Francis: Abingdon, UK, 2017.

25. Hall, C.M. Tourism and Social Marketing; Routledge: Abingdon, UK, 2014.

26. Tourism Western Australia. Domestic Visitation Fast Facts-September 2017; Government of Western Australia: Perth, Australia, 2017.

27. Tourism Western Australia. International Visitation Fast Facts-September 2017. T. W. Australia; Government of Western Australia: Perth, Australia, 2017.

28. Sigala, M.; Gretzel, U. Advances in Social Media for Travel, Tourism and Hospitality: New Perspectives, Practice and Cases; Routledge: Abingdon, UK, 2017.

29. Zhou, N. Beautiful one day, pitiful the next: Is 'philausophy' a new low for Australian tourism ads? In The Guardian; Guardian News \& Media Limited; Available online: https://www.theguardian.com/media/2019/ oct/30/australia-latest-tourism-ad-have-we-reached-a-new-low-philausophy (accessed on 10 January 2020).

30. Kasabov, E.; Peng, Y. Understanding e-Word of Mouth at Chinese Social Networking Sites. In Marketing Challenges in a Turbulent Business Environment; Springer: Berlin/Heidelberg, Germany, 2016; pp. 691-692.

31. Greeven, M.J.; Wei, W. Business Ecosystems in China: Alibaba and Competing Baidu, Tencent, Xiaomi and LeEco; Routledge: Abingdon, UK, 2017.

32. Tuan, Y.-F. Space and Place: The Perspective of Experience; University of Minnesota Press: Minneapolis, MN, USA, 1977.

33. Jing, G.; Gretzel, U. A new cultural revolution Chinese consumers' internet and social media use. In Advances in Social Media for Travel, Tourism and Hospitality; Sigala, M., Gretzel, U., Eds.; Routledge: London, UK, 2018.

34. Choe, Y.; Kim, J.; Fesenmaier, D.R. Use of social media across the trip experience: An application of latent transition analysis. J. Travel Tour. Mark. 2017, 34, 431-443. [CrossRef]

35. Yoo, K.-H.; Gretzel, U. Influence of personality on travel-related consumer-generated media creation. Comput. Hum. Behav. 2011, 27, 609-621. [CrossRef]

36. Shao, G. Understanding the appeal of user-generated media: A uses and gratification perspective. Internet Res. 2009, 19, 7-25. [CrossRef]

37. MacCannell, D. Tourist agency. Tour. Stud. 2001, 1, 23-37. [CrossRef]

38. Munar, A.M.; Jacobsen, J.K.S. Motivations for sharing tourism experiences through social media. Tour. Manag. 2014, 43, 46-54. [CrossRef]

39. Crowe-Delaney, L. Deconstructing the staged and existential authentic of rurality in Japan. Int. J. Tour. Anthropol. 2018, 6, 255-275. [CrossRef]

40. Jalilvand, M.R.; Samiei, N. The impact of electronic word of mouth on a tourism destination choice: Testing the theory of planned behavior (TPB). Internet Res. Electron. Netw. Appl. Policy 2012, 22, 591-612. [CrossRef]

41. Bosangit, C.; Dulnuan, J.; Mena, M. Using travel blogs to examine the postconsumption behavior of tourists. J. Vacat. Mark. 2012, 18, 207-219. [CrossRef]

42. Yang, J.; Leskovec, J. Modeling information diffusion in implicit networks, Data Mining (ICDM). In Proceedings of the 2010 IEEE 10th International Conference on Data Mining, Sydney, Australia, 13-17 December 2010; pp. 599-608.

43. Green, J.R.; Laffont, J.-J. Incentives in Public Decision Making; Elsevier North-Holland: Amsterdam, The Netherlands, 1979.

44. Woo, J.; Chen, H. Epidemic model for information diffusion in web forums: Experiments in marketing exchange and political dialog. SpringerPlus 2016, 5, 1-19. [CrossRef] 
45. Gould, P.R. Spatial Diffusion, Resource Paper No. 4; Association of American Geographers: Washington, DC, USA, 1969.

46. Song, H.; Li, G. Tourism demand modelling and forecasting-A review of recent research. Tour. Manag. 2008, 29, 203-220. [CrossRef]

47. Zhang, Z.; Ye, Q.; Law, R.; Li, Y. The impact of e-word-of-mouth on the online popularity of restaurants: A comparison of consumer reviews and editor reviews. Int. J. Hosp. Manag. 2010, 29, 694-700. [CrossRef]

48. Huang, A.H.; Chen, K.; Yen, D.C.; Tran, T.P. A study of factors that contribute to online review helpfulness. Comput. Hum. Behav. 2015, 48, 17-27. [CrossRef]

49. Qazi, A.; Syed, K.B.S.; Raj, R.G.; Cambria, E.; Tahir, M.; Alghazzawi, D. A concept-level approach to the analysis of online review helpfulness. Comput. Hum. Behav. 2016, 58, 75-81. [CrossRef]

50. Butler, R.W. The concept of a tourist area cycle of evolution: Implications for management of resources. Can. Geogr. Le Géographe Canadien 1980, 24, 5-12. [CrossRef]

51. Baggio, R.; Scott, N.; Cooper, C. Network science: A Review Focused on Tourism. Ann. Tour. Res. 2010, 37, 802-827. [CrossRef]

52. Leiper, N. The framework of tourism: Towards a definition of tourism, tourist, and the tourist industry. Ann. Tour. Res. 1979, 6, 390-407. [CrossRef]

53. Faulkner, B.; Russell, R. Chaos and complexity in tourism: In search of a new perspective. Pac. Tour. Rev. 1997, 1, 93-102.

54. Sheng, L. Regional competition and sustainable development: A game theory model for tourism destinations. Eur. Plan. Stud. 2011, 19, 669-681. [CrossRef]

55. Baggio, R. Symptoms of complexity in a tourism system. Tour. Anal. 2008, 13, 1-20. [CrossRef]

56. Dickinger, A.; Lalicic, L. Tourist driven innovations in social media. In Advances in Social Media for Travel, Tourism and Hospitality: New Perspectives Practice and Cases; Sigala, M., Gretzel, U., Eds.; Routledge: London, UK, 2017.

57. Naimzada, A.K. Networks, Topology and Dynamics: Theory and Applications to Economics and Social Systems; Naimzada, A.K., Stefani, S., Torriero, A., Eds.; Springer: Berlin/Heidelberg, Germany, 2009.

58. Liu, H.; Wu, L.; Li, X. Social Media Envy: How Experience Sharing on Social Networking Sites Drives Millennials' Aspirational Tourism Consumption. J. Travel Res. 2018, 58, 355-369. [CrossRef]

59. McWha, M.; Frost, W.; Laing, J. Travel writers and the nature of self: Essentialism, transformation and (online) construction. Ann. Tour. Res. 2018, 70, 14-24. [CrossRef]

60. Pardo-García, C.; Coll-Serrano, V.; Rausell-Köster, P.; Pérez Bustamante-Yábar, D. Cultural attitudes and tourist destination prescription. Ann. Tour. Res. 2018, 71, 59-61. [CrossRef]

61. Wang, Y.; Davidson, M. Pre- and Post-Trip Perceptions: An Insight into Chinese Package Holiday Market to Australia. J. Vacat. Mark. 2010, 16, 111-123. [CrossRef]

62. Population Australia. Population of Western Australia 2020. Available online: http://www.population.net. au/population-of-western-australia/ (accessed on 10 January 2020).

63. ABS, Australian Bureau of Statistics. W.A. 2017. Available online: http://stat.abs.gov.au/itt/r.jsp?databyregion (accessed on 18 August 2019).

64. Tourism WA. Domestic Visitation-Fast Facts-Year Ending September 2018; Tourism WA-Strategy and Research: Perth, Australia, 2018; p. 11.

65. Tourism WA. International Visitation-Fast Facts-Year Ending September 2018; Tourism WA-Strategy and Research: Perth, Australia, 2018; p. 11.

66. Pilat, L. WA Government's Million Dollar Plan to Attract More Chinese Tourists. WAtoday. 2018. Available online: https://www.watoday.com.au/national/western-australia/wa-government-s-million-dollarplan-to-attract-more-chinese-tourists-20181111-p50fe5.html (accessed on 10 January 2020).

67. Freeman, L.C. Centrality in social networks conceptual clarification. Soc. Netw. 1978, 1, 215-239. [CrossRef]

68. Lambert, D. Zero-Inflated Poisson Regression, with an Application to Defects in Manufacturing. Technometrics 1992, 34, 1-14. [CrossRef]

69. Lee, Y.-G.; Lee, J.-D.; Song, Y.-I.; Lee, S.-J. An in-depth empirical analysis of patent citation counts using zero-inflated count data model: The case of KIST. Scientometrics 2007, 70, 27-39. [CrossRef]

70. Plotnikova, T.; Rake, B. Collaboration in Pharmaceutical Research: Exploration of Country-Level Determinants; Springer-Verlag: Berlin/Heidelberg, Germany, 2014; Volume 98, pp. 1173-1202. 
71. Sidone, O.J.G.; Haddad, E.A.; Mena-Chalco, J.P. Scholarly publication and collaboration in Brazil: The role of geography. J. Assoc. Inf. Sci. Technol. 2017, 68, 243-258. [CrossRef]

72. Long, J.S. Regression Models for Categorical and Limited Dependent Variables. In A Handbook of Statistical Analyses Using R; Everitt, B.S., Hothorn, T., Eds.; Sage Publications: Thousand Oaks, CA, USA, 1997.

73. Zeileis, A.; Kleiber, C.; Jackman, S. Regression models for count data in R. J. Stat. Softw. 2008, 27, 1-25. [CrossRef]

74. Borgatti, S.P.; Everett, M.G.; Freeman, L.C. Ucinet for Windows: Software for Social Network Analysis; Analytic Technologies: Harvard, MA, USA, 2002.

75. Ziv, N.D.; White, K.-A. Social Bookmarking on a Company's Intranet: A Study of Technology Adoption and Diffusion. In Handbook of Social Network Technologies and Applications; Furht, B., Ed.; Springer US: Boston, MA, USA, 2010; pp. 691-711.

76. Schmallegger, D.; Carson, D. Blogs in tourism: Changing approaches to information exchange. J. Vacat. Mark. 2008, 14, 99-110. [CrossRef]

77. Cha, M.; Kwak, H.; Rodriguez, P.; Ahn, Y.-Y.; Moon, S. Analyzing the video popularity characteristics of large-scale user generated content systems. IEEE/ACM Trans. Netw. 2009, 17, 1357-1370.

78. Chinese Tourism Academy. Annual Report of China Inbound Tourism Development 2013; Chinese Tourism Academy: Beijing, China, 2013.

79. Chinese Tourism Academy. Annual Report of China Inbound Tourism Development 2014; Chinese Tourism Academy: Beijing, China, 2014.

80. Shirky, C. Here Comes Everybody: The Power of Organizing without Organizations; Penguin Press: New York, NY, USA, 2008.

81. Wang, Y.; Fesenmaier, D.R. Towards understanding members' general participation in and active contribution to an online travel community. Tour. Manag. 2004, 25, 709-722. [CrossRef]

(C) 2020 by the authors. Licensee MDPI, Basel, Switzerland. This article is an open access article distributed under the terms and conditions of the Creative Commons Attribution (CC BY) license (http://creativecommons.org/licenses/by/4.0/). 